Angela Kawińska

Independent scholar

\title{
E-sport och den svenska kulturen
}

\author{
E-sports and Swedish Culture
}

The aim of this study is to familiarize readers with the term e-sports and to show the influence which selected elements of Swedish culture have had on it. The article explores the definition of e-sports, its history and actual state. I concentrated especially on a document named the Svensk $e$-sports Code of Conduct. Rules and tips contained in this document were made and gathered in order to support an open and welcoming environment in e-sports.

Key words: e-sports, electronic sports, players, Svensk e-sports code of conduct, computer games

Nyckelord: e-sport, elektronisk sport, spelare, Svensk e-sports code of conduct, dataspel

\section{Inledning}

Mitt mål med den här artikeln är att göra fler läsare bekanta med vad e-sport är och visa sammanhanget mellan svenskarnas mentalitet, levnadsvillkor och deras inverkan på e-sportens område. Jag vill analysera vissa aspekter av den svenska kulturen och deras påverkan på skapandet av och innehållet i dokumentet Svensk $e$-sports Code of Conduct. I artikeln försöker jag svara på frågan om vilka aspekter av den svenska kulturen som hade den största inverkan på det beskrivna dokumentet och på vilket sätt de påverkade det.

I artikeln förklarar jag först vad e-sport är, uppger e-sports historia och den aktuella situationen. Sedan beskriver jag de regler och tips som finns i Svensk e-sports Code of Conduct för att koppla dem till utvalda aspekter av den svenska kulturen. I artikeln vill jag svara på följande frågor:

- Varför är e-sport viktig i Sverige?

- Vilka svenska dokument som är relaterade till e-sport är betydande i kultursammanhang?

- Vilka aspekter av svensk kultur är särskilt viktiga för skapandet av och innehållet i sådana dokument? 
- Vilka organisationer påverkar utvecklingen av e-sport i Sverige?

Jag tror att e-sport kommer att bli mer och mer betydande inom flera områden, till exempel sociologi eller ekonomi och det är viktigt att börja forska om denna bransch.

\section{E-sport - begrepp och historia}

E-sport är ett relativt nytt och invecklat fenomen, därför är det svårt att hitta en enhetlig definition för det. Svenska e-sportföreningen anger att "e-sport är en förkortning av elektronisk sport och ett samlingsnamn för alla tävlingar som utförs $i$ en virtuell miljö" (Svenska e-sportföreningen). Nationalencyklopedin belyser att "begreppet e-sport avser både fenomenet i stort och enskilda evenemang. E-sport är på många sätt likt tävlan i organiserad idrott. Utövarna blir berömda och kan vinna stora pengavinster, sponsorer ställer sig bakom både enskilda tävlande och lag, och evenemangen sänds ut till en stor publik" (Nationalencyklopedin) medan det i Svensk e-sports Code of Conduct förklaras att varje människa som tävlingsinriktat spelar mot andra i ett datorspel kan betraktas som e-sportare, såväl proffs som nybörjare (Englin [i.s.]).

Den första kända videospelstävlingen ägde rum den 19:e oktober 1972. På Stanfords universitet samlades över 20 studenter för att spela mot varandra i ett av de första datorspelen - Spacewar. Det var enkelt, men man fann nöje i det. Spelet skapades av några studenter på Massachusetts Institute of Technology. Datamaskinerna, vilka man då spelade på, vägde cirka 1200 pund och de fanns bara på akademiska centra (Li 2016: 7). Förstapriset i denna tävling var ett års abonnemang på Rolling Stone (Rolling Stone). 1985 började Guinness Book of World Records inkludera en lista över de bästa resultaten i de mest kända videospelen (Oxford American).

På 1990-talet blev spelen mer komplicerade och grafiken blev bättre. Datorer och spelkonsoler blev avsevärt mindre och billigare, följaktligen hade fler och fler människor råd att köpa en. Den snabba utvecklingen av internet under den perioden orsakade att människor jorden runt började spela med eller mot varandra. Till följd av det började en ny typ av samhälle att utvecklas (Li 2016: 8).

Starcraft publicerades 1998 av Blizzard Entertainment. Det var ett revolutionerande realtidsstrategi-datorspel. Fler än 1,5 miljoner kopior såldes under det första året efter publiceringen (Blizzard Entertainment). Människor började söka efter billiga underhållningssätt och därför verkade datorspel ideala. Många internetcaféer skapades, där människor träffades inte bara för att spela utan också för att träffa andra spelare (Li 2016: 29).

I mars 2007 skapades Justin.tv - en av de första webbplatserna för direktsänd videoströmning. En av skaparna, Justin Kan, band en kamera till sitt huvud och 
visade sitt liv för tittare nästan dygnet runt. Det som attraherade tittarna var att man kunde chatta med Kan och de andra tittarna. Följaktligen kände man sig som en del av ett nytt slags samhälle. Efter en kort period började många människor att be om möjligheten att skapa sina egna kanaler. Justin.tv var populär men skaparna började tänka på nya möjligheter, som e-sport kan erbjuda. Därför bestämde de sig i juni 2011 för att sätta igång en ny domän som koncentrerade sig på e-sport Twitch.tv (Li 2016: 61-66). Fram till februari 2013 hade Twitch mer än 28 miljoner unika tittare (Twitch.tv). Twitch har blivit ett oumbärligt inslag i e-sporten. Många proffs streamar för att det är ett bra sätt att kommunicera med sina fans och tjäna extra pengar.

I juli 2010 utgav Blizzard den andra delen av sitt framgångsrika spel - Starcraft II. Det blev en enorm succé med 3 miljoner sålda kopior inom en månad (Eurogamer). Spelet var från början designat att vara tävlingsinriktat och bra att titta på. Onlinepubliken växte väldigt snabbt. Tittarantalet gick från 1,8 miljoner 2010 till 11,7 miljoner 2012 (Li 2016: 40-47).

Starcrafts popularitet var stor, men en ny konkurrent började att tillta i styrka. I oktober 2009 utgav Riot Games sitt första spel - League of Legends. Detta spel påverkade e-sporten på ett betydande sätt. League of Legends är ett spel vilket man spelar med ett team och det har uppmuntrat många människor, eftersom man kan spela med sina vänner eller träffa nya kompisar online. Sommaren 2011 tittade fler än 1,6 miljoner människor på det första League of Legends World Championships på DreamHack i Sverige. League of Legends växte och blev det populäraste datorspelet i världen med 67 miljoner spelare varje månad under 2014 (Li 2016: 79-83).

Antalet turneringar och beloppen inom e-sport ökar nästan varje år. Under de senaste 20 åren har fler och fler börjat intressera sig för e-sport, vilket har orsakat att fler turneringar organiseras. Stor popularitet har också attraherat många sponsorer. Följaktligen finns det mer och mer pengar i e-sportbranschen (e-sports earnings).

Enligt esportsearnings.com har svenska spelare tjänat mer pengar på e-sportsturneringar än e-sportare från andra europeiska länder. Dota 2-spelaren Gustav 's4' Magnusson har själv tjänat över 1,6 miljoner dollar. En annan svensk Dota 2-spelare, Ludwik 'zai' Wåhlberg, har tjänat över 1,4 miljoner dollar och han är bara 20 år gammal (e-sports earnings).

I Sverige finns många föreningar som sysslar med e-sport. I oktober 2008 startades Svenska E-sportföreningen (SESF). Syftet med föreningen är att främja e-sport i Sverige. Den är öppen för alla som är intresserade av e-sport (Svenska e-sportföreningen).

2018 publicerade Paypal och SuperData en rapport som visar att i Europa är det Sverige, Frankrike, Storbritannien och Ryssland som har den största publiken och gör den största vinsten på e-sport. Det måste påpekas att Sveriges befolkning 
är mycket mindre i jämförelse med de andra ovannämnda länderna. Dessutom uppgick vinsten av e-sport i Sverige till 40 miljoner dollar under 2016. Rapporten pekar också på att Sverige är det land som har det största proportionella deltagandet av kvinnor inom e-sportområdet. Enligt rapporten är 24 procent av alla svenska spelare kvinnor medan motsvarande siffra i hela Europa bara är 16 procent (Public Relations).

\section{Svensk e-sports code of conduct}

Svensk e-sports Code of Conduct är ett dokument, som innehåller etiska regler för e-sportare och arrangörer av e-sportarrangemang. Det omfattar också några tips för föräldrar till e-sportare. Det tog mer än ett år och samarbete mellan tolv svenska e-sportorganisationer för att skapa det. Dokumentet togs fram inom projektet Respect All, Compete, som Allmänna Arvsfonden finansierade. Målet med projektet var att bilda en gynnsam utveckling av e-sport och att skapa en mer välkomnande attityd och ett bättre klimat inom e-sporten.

På sin internetsida påpekar Respect All, Compete - projektets skapare att e-sport ger goda möjligheter för jämlikhet. Ålder, kön, kroppstyp eller samhällsklass bör inte spela någon roll i en digital miljö. Tyvärr motsvarar teorin inte alltid verkligheten. Sociala konventioner hindrar en jämlik utveckling för alla. Projektets skapare ville undersöka varför det finns problem med jämlikhet inom e-sporten och vilka åtgärder alla kan vidta för att förbättra situationen (Respect All, Compete).

\section{Barnuppfostran i Sverige}

Sättet på vilket man uppfostrar barn i Sverige är speciellt och kan verka egendomligt för människor som kommer från andra kulturer. Exempelvis har Republiken Polens Ambassad i Stockholm upprättat en broschyr, där det förklaras hur man bör förbereda sig inför en resa med barn till Sverige. Det står i broschyren att på grund av kulturella och historiska aspekter är lagstiftningar, som gäller skydd för barn, olika i dessa två länder. Polens ambassad i Stockholm varnar polska medborgare att under deras vistelse i Sverige måste de känna till och följa de lokala reglerna. I annat fall kan det orsaka allvarliga konsekvenser för hela familjen (Republiken Polens Ambassad i Stockholm).

När man jämför svenska och sydeuropeiska kulturmönster kan man också se stora skillnader. En framgångsrik uppfostran i Sverige betyder att ungdomarna är självständiga, ansvariga och steg för steg intar sin plats i kollektivet. I Sydeuropa däremot är det viktigaste målet med uppfostran att barnen anpassar sig till 
familjestrukturen (Sjögren 1985: 40). Marianne Cederberg som är barnpsykiater beskriver i en undersökning att ambitionen att tidigt göra barn självständiga är något utmärkande för Sverige:

I Sverige har vi [...] extrema förväntningar på självständighet hos barn från tidig ålder och föräldrar ser trotsålders-barnets uttryck för kraftfullhet och frimodighet som något glädjande och önskvärt (Aronsson: 29).

Nuvarande uppfostringsmetoder har fasta fundament. 1900 utgavs Barnets århundrade, som revolutionerade sättet på vilket man begrep barn och deras uppfostran. Trots att boken är mer än 100 år gammal finns några av dess idéer fortfarande kvar i det svenska samhället. Bokens författare, Ellen Key, var en svensk författare och pedagog. Några regler som Ellen Key ansåg som viktiga i uppfostran anges nedan:

Endast genom att hålla sig själf i en oaflåtlig tillväxt, under en oaflåtlig växelverkan med det bästa inom sin egen tid, blir man småningom ett någorlunda godt sällskap för sina barn (Key 1900: 7).

Redan i början av 1900-talet visste Ellen Key hur viktigt det är att följa med sin tid. Om man inte ägnar tillräckligt med tid och vilja för att uppdatera sig är det nästan omöjligt att skapa en bra relation med sitt barn. Det är meningslöst för barn att berätta för sina föräldrar om saker, som föräldrarna inte kommer att förstå. Därför uppmuntras föräldrarna i Svensk e-sports Code of Conduct att intressera sig för e-sport. Det kan kännas ansträngande, särskilt med tanke på att e-sport utvecklas så fort, men med hjälp av ett systematiskt arbete och engagemang kommer man att uppnå målet, vilket är bättre kontakt med sitt barn. I detta dokument föreslås det också att föräldrar bör försöka spela datorspel eller åka på LAN tillsammans med sina barn. Allt det ska bidra till en bättre relation mellan barn och föräldrar.

I en annan del av texten skriver Ellen Key att "den enda rätta utgångspunkten vid ett barns uppfostran till social människa är att behandla det som en sådan, samtidigt med att man stärker barnets mod att blifva en individuell människa" (Key 1900: 11-12).

Ellen Key påstod att man måste stödja sitt barns mod och lust att bli en individuell människa, eftersom det kommer att hjälpa barnet att bli en bättre medlem i samhället. Att uppdatera sig spelar återigen en viktig roll, eftersom man genom att göra det också kan börja förstå sitt barn bättre. Till exempel kan man ta reda på att online-miljön också har blivit en plats, där socialt umgänge sker. Således börjar man förstå att e-sport inte bara är ett underhållningssätt utan att den har en stor betydelse i utvecklingen av barns sociala kompetens. Att låta ett barn vara med i ett team eller en förening kommer också att ha fördelaktig inverkan på barnets 
sociala förmåga. Dessutom är det ett bra sätt att förbereda barnet för att leva i ett demokratiskt samhälle.

Vill man åstadkomma människor, icke massa, då gäller det att [...] utveckla alla de impulser, af hvilka människans styrka och värde bero! Och detta sker endast genom att redan från tidigaste år lära barnet det egna valets frihet och fara, den egna viljans rätt och ansvar, den egna pröfningens villkor och uppgift (Key 1900: 73).

Ellen Key uppmuntrade andra att behandla barn som individer. Genom att låta barn ta egna beslut lär man dem vad ansvar är. Föräldrarna bör acceptera barnens individuella beslut om sättet på vilket de tillbringar sin fritid. Även om ens barns intressen verkar konstiga och obegripliga för en borde man acceptera dem, så länge dessa intressen inte skadar andra eller själva barnet. På grund av detta står det i Svensk e-sports Code of Conduct att man bör respektera sitt barns e-sportintresse på samma sätt som andra fritidsintressen. E-sport och datorspel är ett relativt nytt sätt att tillbringa sin fritid på. Det är sannolikt att svenska föräldrar som värderar individualitet kan uppfatta e-sport som en bra möjlighet för deras barn att utveckla sin egenart.

Eftersom individualitet ses som ett viktigt värde är det också mer naturligt för svenskarna att acceptera alla människor, oberoende av deras utseende, ursprung och så vidare. Att vara en individuell, karaktäristisk människa uppfattas som en fördel. Följaktligen visar svenskar generellt mer tolerans mot människor med olika ovanliga egenskaper. Också för den skull uppmuntras underrepresenterade grupper i Svensk $e$-sports Code of Conduct att ta del av e-sportsmiljön. Man ser goda möjligheter och fördelar i egenarten, istället för att behandla den som ett problem eller en fara.

Berggren och Trägårdh hävdar också att såväl individualitet som behov av tillhörighet till en större grupp spelar en stor roll i svenskens kulturella och historiska särdrag (Berggren, Trägårdh 2006: 34). Sammanfattningsvis har det i Sverige varit mycket viktigt att uppfostra barn till självständiga individer som lätt kommer att anpassa sig till att leva i ett demokratiskt samhälle. Det kan man göra genom att stödja deras individuella val, till exempel att vara en del av e-sporten. Men att låta barnet besluta betyder inte att man inte bör intressera sig för och engagera sig i sitt barns fritidsaktivitet.

\section{Jämlikhet}

På den svenska regeringens webbplats kan man läsa att mänskliga rättigheter säkerställer att alla människor är födda fria och lika i rättigheter och värde, oberoende av kultur, land och sammanhang. Efter andra världskriget började För- 
enta Nationerna utarbeta dokument som behandlar de mänskliga rättigheterna. FN-konventionerna från 1966, FN:s allmänna förklaring och Europakonventionen innehåller många rättigheter och friheter. Alla dessa konventioner gäller i Sverige (Sveriges regering).

Universalism och kollektiv solidaritet, som karakteriserar de nordiska samhällena, förorsakar ett specifikt samhällsutvecklingsmönster. En av mönstrets aspekter är trycket på demokratiska styrelseformer kombinerade med en hög social ansvarsnivå, till exempel genom att uppmuntra medborgare till att medbestämma och delta i olika delar av processen för beslutsfattande. En annan aspekt av detta mönster är en social konsensus som gäller lika rättigheter och lika möjligheter för alla, det vill säga att man lägger stor vikt vid frågor som jämställdhet samt kamp mot diskriminering av kvinnor och andra sociala grupper, såsom sexuella eller etniska minoriteter (Anioł 2013: 29-30).

Sverige hamnade på fjärde plats i The Global Gender Gap 2016 Index. Målet med detta index är att visa vilka länder som är ledande i sin region vad gäller att fördela resurser på ett rättvist sätt mellan kvinnor och män. Bara Island, Finland och Norge hade bättre resultat i denna rangordning. Det att Sverige placerades så högt $\mathrm{i}$ indexet visar att jämställdhet är en av Sveriges starka sidor (The Global Gender Gap 2016 Index).

Kvinnors stora deltagande på arbetsmarknaden i Sverige är framförallt ett resultat av kulturella förändringar. Det visar att man har minskat den stereotypiska uppfattningen om kvinnliga och manliga förebilder. Det betyder också att kvinnor har ännu större personliga och sociala förhoppningar. Staten främjar inte bara kvinnors deltagande på arbetsmarknaden, utan också deras närvaro i det offentliga och politiska livet och det orsakar att jämställdheten i Skandinavien är mycket bättre än i andra länder (Anioł 2013: 45-46). Redan på medeltiden var skandinaviska kvinnors status relativt hög. Kvinnor från olika samhällsskikt kunde bli ägare av mark. Framförallt skedde det genom äktenskap och arv. Mannen hade kontrollen över sin hustrus egendomar men han behövde hennes samtycke för att disponera över dem. Dessutom var skandinaviska änkor mest oberoende i hela Europa. De kunde fortsätta att odla sin jord själva om deras make dog. De hade också mer att säga till om när det gällde ekonomiska transaktioner och juridiska konflikter än andra kvinnor runtom i världen (Helle 2003: 306-307).

Man kan tydligt se att man i Svensk e-sports Code of Conduct lägger stor vikt vid jämlikhet och verkan mot diskriminering. Redan i förordet står det att man vill utnyttja e-sportens stora potential att inkludera nästintill alla. Dessutom bidrar nästan samtliga regler i dokumentet till minskning av diskriminering och dokumentet är i sig självt ett verktyg för att främja tolerans för minoriteter. Det påpekas hur viktigt det bör vara för arrangörer av ett evenemang att alla ska känna sig välkomna och trygga, därför att alla människor, oavsett kön, ursprung osv., har 
rätt att känna sig jämlika. Följaktligen har alla lika rätt att utöva e-sport och genom det dokumentet vill man uppmuntra underrepresenterade grupper att delta. Exempelvis erkänns det att det inte finns så många kvinnor inom e-sporten, men man försöker att hitta ett sätt att övertyga dem att vara med. Två av förslagen är att organisera avgränsade tävlingar och att skapa platser där e-sport kan introduceras för kvinnor. Man bör göra det för att låta dem känna sig trygga och då blir det lättare för dem att börja tävla och förena sig med e-sportsamhället. Inkluderande lokaler är ett sätt att skapa lika möjligheter för alla. Det är människors rätt att kunna vara med på ett öppet evenemang men följaktligen måste lokalerna anpassas till alla deltagare.

Den höga sociala ansvarsnivån är också påfallande i dokumentet. Det är e-sportarna själva som har skapat detta dokument och genom det bidrar de till positiva förändringar i e-sportsmiljön. De uppmuntrar också andra att engagera sig och skapa nya, bättre vanor. Dessutom föreslås det i dokumentet att be streamare ${ }^{1}$ och kända spelare om hjälp för att stödja jämlikheten på sociala medier. Man försöker att främja de gamla kulturella värdena med hjälp av moderna kanaler för att lättare nå den nya generationens uppmärksamhet.

Demokratiska styrelseformer föreslås också och verkar vara viktiga i dokumentet. Det antyds att det kan vara en bra tanke att fråga deltagarna om vad de förväntar sig från ett event och kanske ändra något om det verkar fördelaktigt. Vidare står det att det bör finnas några anställda som tillhör underrepresenterade grupper för att ta reda på deras synpunkter. Man bör också låta de anställda ta del i skapandet av regler. Genom detta ges organisatörerna en möjlighet att bredda sitt perspektiv och kanske kommer de att förbättra något. Om man låter människor ta del i olika beslut känner de sig dessutom mer ansvariga och är mer engagerade.

Sammanlagt är det väsentligt att verka mot diskriminering och att stödja grupper som är underrepresenterade i e-sporten. Man kan iaktta en hög social ansvarsnivå, eftersom det finns många människor som genom olika åtgärder engagerar sig i förbättringen av e-sportsmiljön. Man lägger också stor vikt vid att engagera många $i$ att skapa regler och att ta beslut.

\section{Konfliktundvikande}

I Skandinavien finns det en lång tradition av konfliktundvikande. Man kan även säga att det är någonting som utmärker de skandinaviska länderna (Chacińska 2018: 77-78). Orsaken till det svenska konfliktundvikandet kan man söka i många olika faktorer. En av dem är att Sverige har en lång historia av fred. Över 200 år

1 En person som driver en mediekanal med innehåll som strömmas till publiken över internet. 
utan krig har skapat en viss mentalitet. En annan faktor är att den sociala och ekonomiska utvecklingen under moderna tider har varit stabil för hela befolkningen. Följaktligen har svenskarna inte varit i stort behov av att konkurrera eller gräla med varandra (Daun 1994: 114).

Vad gäller utrikespolitik är de skandinaviska länderna kända för solidaritet, allmän välfärd, mänskliga rättigheter, konsensus, stöd för rättigheter och internationella organisationer, social rättvisa och att lösa problem med fredliga medel. De är också ofta engagerade som medlare i internationella konflikter (Anioł 2013: 153, 163).

Många av de värden som uppskattas i Sverige har framkallats av kulturella och geografiska villkor. Exempelvis kommer den starka ansvarskänslan från den protestantiska etiken, som hade en stor betydelse inom detta område. Emellertid orsakade livet i den hårda naturmiljön att människor vet hur viktigt det är att följa de grundläggande reglerna, som gäller det sociala livet. Det vill säga ärlighet, tillförlitlighet, solidaritet och att uppfylla sina avtal (Anioł 2013: 26).

I Svensk e-sports Code of Conduct förväntar man sig av arrangörerna att de förbereder konkreta och tydliga regler för ett evenemang, eftersom det på detta sätt blir lättare för spelarna att följa dem. Man bör lägga märke till att spelarna måste godta de givna villkoren för att delta i eventet. Personuppgifter kan fordras i anmälan. Det förorsakar att deltagarna måste ta eget ansvar och vara tillförlitliga för att inte bryta avtalet mellan dem och organisatörerna. Man förutsätter att alla deltagare är ärliga, men om någon bryter mot bestämmelserna är det viktigt att förklara varför den blir straffad. Det är också viktigt att försäkra sig om att alla människor som är engagerade i evenemanget är solidariska när det gäller etiska regler.

En annan anledning till det svenska konfliktundvikandet kan också vara det speciella sättet på vilket barn uppfostras i Sverige. Man förväntar sig att föräldrar och dagispersonal ska vara förebilder för barn och visa dem hur man tyglar känslor eller riktar dem åt ett annat håll (Daun 1994: 97-98). På 1960-talet skrev Herbert Hendin att svenska barn inte tillåts att ge uttryck för sin ilska på samma öppna sätt som amerikanska barn. Han framhöll också att: "vara tyst och lugn är något av ett svenskt ideal" (Hendin 1964: 67). I många länder är det normalt att uttrycka sina starka känslor, men om man gör det i Sverige kan någon annan uppfatta det som ett angrepp. Åke Daun, som var en svensk professor i etnologi, påstod att: "svenskar tenderar i många hänseenden att se ned på starka och spontana känslouttryck. Det uppfattas som löjligt och barnsligt” (Daun 1994: 135).

I dokumentet står det att det är omöjligt att inte ha negativa känslor, men att man ska försöka att uttrycka dem på rätt sätt. Man uppger några förslag på hur man ska hantera sina känslor. Till exempel ska man fokusera på att förbättra sina förmågor istället för att klaga. Det är naturligtvis idealt för organisatörerna om det inte finns några problem och konflikter på ett evenemang. Därför försöker 
man uppmuntra deltagarna till ett positivt beteende. Ett av argumenten är att deras goda uppförande kan förbättra inte bara klimatet inom e-sporten utan också deras chanser att vinna. Det påpekas att inte alla uppfattar språk på samma sätt och att man måste vara försiktig för att inte såra någon.

De flesta svenskar försöker anpassa sig till kollektivet, eftersom gruppen erbjuder en känsla av säkerhet för socialt osäkra individer. Därför känner många svenskar ett behov av att komma överens med kollektivet och att vara konforma (Daun 1994: 170). Det föreslås i dokumentet att det är en bra idé att vara med i ett lag eller en e-sportförening. Man känner sig säkrare om man har kompisar som sysslar med samma sak, men om man bestämmer sig för att gå med i ett team är man skyldig att följa deras principer. Det kan vara en bra motivation, eftersom man ibland måste ändra sitt dåliga beteende för att man är angelägen om att stanna i gruppen.

Åke Daun skrev också att: "när svenskar möts försöker de i allmänhet etablera en relation karakteriserad av ömsesidig förståelse, samstämmighet, konsensus och vänskaplighet" (Daun 1994: 125). Därför framhålls i dokumentet hur viktigt det är att visa empati. Man föreslår att istället för att klaga på nya spelare kan man vara vänlig och exempelvis fråga dem om de behöver hjälp. Om man är med i ett team är det också självklart att lagkamrater försöker förstå varandra bättre och komma överens.

Sammanfattningsvis är svenskar kända för ärlighet, konsensus och att lösa problem på ett fredligt sätt. I Svensk e-sports Code of Conduct värderar man dessa aspekter och genom olika metoder försöker man uppmuntra spelare att göra likadant.

\section{Ordning och reda}

Formaliserad kollektiv samverkan har en lång historia i Sverige. Byalaget existerade under hundratals år som en förening av självägande bönder. De var tvungna att följa bestämda regler som kallades för byordning (Daun 1994: 126). Daun påstod att de flesta svenskar har "samma personlighetssyndrom: en utpräglad betoning av förnuft, saklighet och fakta, ordning och reda" (Daun 1994: 156). Han skrev också att det är påfallande hur mycket man i den svenska kulturen anstränger sig för att uppnå något som man kan kalla för "god ordning". Dessutom underkastar sig de flesta svenskar de bestämda reglerna, eftersom de tror att lagstiftarna är dem lika (Daun 1994: 163). Även när det gäller fritidsaktiviteter är det normalt att följa ett mönster: följa instruktioner, be om ordet, sjunga från notblad, skriva protokoll, osv. Aktiviteterna är ofta välplanerade. De har förutbestämda rutiner eller scheman (Daun 1994: 168).

I min uppfattning är själva skapandet av Svensk e-sports Code of Conduct ett bevis på att svenskar tycker om ordning. Man förberedde detta dokument för att 
ha alla de viktigaste reglerna och tipsen på samma ställe. I Sverige är man van att följa ett givet mönster, därför verkar det lättare att följa de etiska reglerna och tipsen om de är i form av ett välplanerat dokument. Samma tendens visas när det gäller skapandet av en handlingsplan. Det föreslås att man förbereder en sådan för att snabbare och bättre hantera problematiska situationer, som kan uppstå.

Om man läser Svensk e-sports Code of Conduct kan man dessutom märka att författarna till dokumentet också är e-sportare. Därmed gäller alla regler på samma sätt också dem. Följaktligen känns det rättvist att alla har lika rättigheter och plikter.

\section{Slutsatser}

E-sport är ett ungt men snabbt växande område och det finns ännu inte så många dokument som reglerar hur man ska bete sig på evenemang eller i en virtuell miljö. Följaktligen kände svenska e-sportare ett behov av att skapa Svensk e-sports Code of Conduct för att samla de viktigaste reglerna och tipsen på samma plats. Redan här visas en av de beskrivna aspekterna - att svenskar tycker om att följa mönster och regler.

I dokumentet visas att det finns några kulturella aspekter som påverkade att man har uppskattat samma värden i många år. Ellen Keys idéer har genomsyrat svensk mentalitet och därför värderar man sina barns individualitet och försöker att följa med sin tid för att skapa en bättre relation med dem. Å andra sidan förorsakar det speciella sättet på vilket man uppfostrar barn att de flesta svenskar är försiktiga med att uttrycka sina känslor. Universalism och kollektiv solidaritet är orsaken till att man kommer överens om lika rättigheter och lika möjligheter för alla. Därför är det så viktigt för skaparna av Svensk e-sports Code of Conduct att främja tolerans.

Dokumentet finansierades av Allmänna Arvsfonden, som är en statlig fond och det betyder att fonden stödjer initiativ som på något sätt representerar svenska värden. För att få pengar av Allmänna Arvsfonden, måste en verksamhet uppfylla olika kriterier. Exempelvis måste den ge alla människor lika rättigheter och möjligheter. Alla måste ha möjlighet till insyn i och påverkan på verksamheten. Dessutom ska verksamheten arbeta aktivt för att alla ska kunna delta i och bidra till verksamheten och känna sig välkomna (Allmänna Arvsfonden).

Till de viktigaste aspekter som har påverkat svensk mentalitet hör den protestantiska etiken, en lång period utan krig och det speciella sättet att uppfostra barn. Följaktligen värderar man ärlighet, kompromissvilja, demokrati, individualitet osv. I Svensk e-sports Code of Conduct försöker man genom regler och tips att uppmuntra andra till att kultivera alla dessa värden som $i$ århundraden har varit grundläggande i Sverige. 


\section{Litteratur}

Ahlberg, C. (ed.). (2004). Det svenska samhället 1720-2000. Böndernas och arbetarnas tid. Lund: Studentlitteratur.

Anioł, W. (2013). Szlak Norden. Modernizacja po skandynawsku. Warszawa: Dom Wydawniczy ELIPSA.

Aronsson, K. (m.fl.) (1984). Barn i tid och rum. Stockholm: Liber.

Berggren, H., Trägårdh, L. (2006). Är svensken människa? Gemenskap och oberoende i det moderna Sverige. Stockholm: Norstedts Förlag.

Chacińska, M. (2018). W służbie ludu i inżynierii społecznej. Gdańsk: Wydawnictwo Uniwersytetu Gdańskiego.

Daun, Å. (1994). Svensk mentalitet. Stockholm: Rabén och Prisma.

Englin, J. [i.s.], Svensk e-sports Code of Conduct, http://www.respectallcompete.se/wp-content/ uploads/2015/11/Svensk-e-sports-Code-of-Conduct.pdf [tillgång: 27.05.2017].

Helle, K. (2003). The Cambridge History of Scandinavia. Prehistory to 1520. Cambridge: Cambridge University Press.

Hendin, H. (1964). Suicide and Scandinavia: A Psychoanalytic Study of Culture and Character. New York och London: Grune \& Stratton Inc.

Key, E. (1900). Barnets århundrade. Stockholm: Albert Bonniers Förlag.

Li, R. (2016). Good Luck Have Fun, The Rise of eSports. New York: Skyhorse Publishing.

Sjögren, A. (1985). Förhållandet till barnen visar kulturskillnader. Invandrare \& Minoriteter 4.

\section{Elektroniska källor}

Arvsfonden: https://www.arvsfonden.se [tillgång: 15.05.2019].

Blizzard Entertainment: http://www.blizzard.com [tillgång: 30.04.2019].

DreamHack: https://www.dreamhack.se [tillgång: 28.04.2019].

Eurogamer: https://www.eurogamer.net [tillgång: 15.04.2019].

E-sports earnings: https://www.esportsearnings.com [tillgång: 30.04.2019].

Nationalencyklopedin: http://www.ne.se [tillgång: 15.04.2019]

Oxford American: http://www.oxfordamericanmag.com [tillgång: 16.04.2019].

Public Relations: https://publicrelations.pl [tillgång: 15.05.2019].

Republiken Polens Ambassad i Stockholm: http://www.sztokholm.msz.gov.pl [tillgång: 14.04.2019].

Respect All, Compete: http://www.respectallcompete.se [tillgång: 14.04.2019].

Riot Games: https://www.riotgames.com [tillgång: 16.04.2019].

Rolling Stone: https://www.rollingstone.com [tillgång: 20.04.2019].

Svenska e-sportföreningen: https://www.sesf.se [tillgång: 25.04.2019].

Sveriges regering: https://www.regeringen.se [tillgång: 18.04.2019].

Twitch.tv: https://blog.twitch.tv [tillgång: 20.04.2019]. 